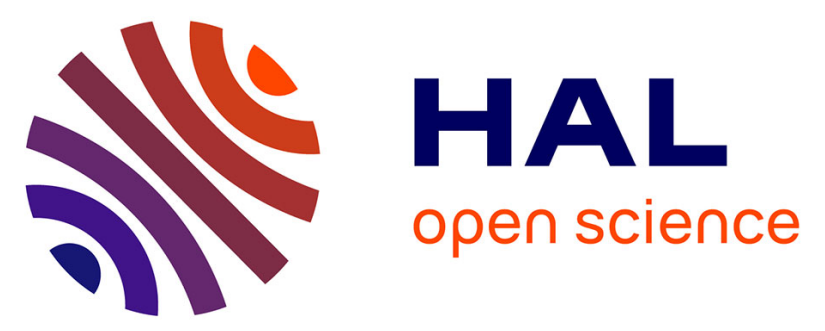

\title{
Solution layer deposition: A technique for the growth of ultra-pure manganese oxides on silica at room temperature
}

\author{
Jérémy Cure, Kilian Piettre, Yannick Coppel, Eric Beche, Jérôme Esvan, \\ Vincent Collière, Bruno Chaudret, Pierre Fau
}

\section{To cite this version:}

Jérémy Cure, Kilian Piettre, Yannick Coppel, Eric Beche, Jérôme Esvan, et al.. Solution layer deposition: A technique for the growth of ultra-pure manganese oxides on silica at room temperature. Angewandte Chemie International Edition, 2016, 55 (9), pp.3027-3030. 10.1002/anie.201509715. hal-01565099

\section{HAL Id: hal-01565099 \\ https://hal.science/hal-01565099}

Submitted on 19 Jul 2017

HAL is a multi-disciplinary open access archive for the deposit and dissemination of scientific research documents, whether they are published or not. The documents may come from teaching and research institutions in France or abroad, or from public or private research centers.
L'archive ouverte pluridisciplinaire HAL, est destinée au dépôt et à la diffusion de documents scientifiques de niveau recherche, publiés ou non, émanant des établissements d'enseignement et de recherche français ou étrangers, des laboratoires publics ou privés. 


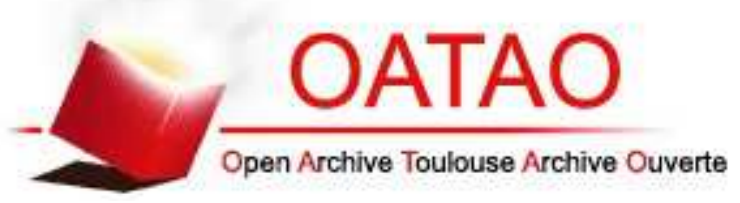

\section{Open Archive TOULOUSE Archive Ouverte (OATAO)}

OATAO is an open access repository that collects the work of Toulouse researchers and makes it freely available over the web where possible.

This is an author-deposited version published in : http://oatao.univ-toulouse.fr/ Eprints ID : 16709

To link to this article : DOI: 10.1002/anie.201509715

URL : http://dx.doi.org/10.1002/anie.201509715

To cite this version : Cure, Jérémy and Piettre, Kilian and Coppel, Yannick and Beche, Eric and Esvan, Jérôme and Collière, Vincent and Chaudret, Bruno and Fau, Pierre Solution layer deposition: A technique for the growth of ultra-pure manganese oxides on silica at room temperature. (2016) Angewandte Chemie International Edition, vol. 55 ( ${ }^{\circ}$ 9). pp. 3027-3030. ISSN 1433-7851

Any correspondence concerning this service should be sent to the repository administrator: staff-oatao@ listes-diff.inp-toulouse.fr 


\title{
Solution Layer Deposition: A Technique for the Growth of Ultra-Pure Manganese Oxides on Silica at Room Temperature
}

\author{
Jérémy Cure, Kilian Piettre, Yannick Coppel,* Eric Beche, Jérôme Esvan, Vincent Collière, \\ Bruno Chaudret, and Pierre Fau*
}

\begin{abstract}
With the ever increasing miniaturization in microelectronic devices, new deposition techniques are required to form high-purity metal oxide layers. Herein, we report a liquid route to specifically produce thin and conformal amorphous manganese oxide layers on silicon substrate, which can be transformed into a manganese silicate layer. The undesired insertion of carbon into the functional layers is avoided through a solution metal-organic chemistry approach named Solution Layer Deposition (SLD). The growth of a pure manganese oxide film by SLD takes place through the decoordination of ligands from a metal-organic complex in mild conditions, and coordination of the resulting metal atoms on a silica surface. The mechanism of this chemical liquid route has been elucidated by solid-state ${ }^{29}$ Si MAS NMR, XPS, SIMS, and HRTEM.
\end{abstract}

$T_{\text {he deposition of metal oxide thin films on supports is a real }}$ challenge in obtaining functional materials of high purity in several applications, such as microelectronics, photovoltaics, and energy storage. To deposit metal oxide layers, three main methods based on vapor deposition processes are commonly used: Physical Vapor Deposition (PVD), Chemical Vapor Deposition (CVD), and Atomic Layer Deposition (ALD) ${ }^{[1]}$ Among them, CVD involves the decomposition of organometallic precursors at high temperature $\left(>250^{\circ} \mathrm{C}\right)$ and low pressure, but generates unwanted byproducts in the growing film. Conversely, ALD processes are considered as the most

[*] Dr. J. Cure, Dr. K. Piettre, Dr. Y. Coppel, V. Collière, Dr. P. Fau CNRS, LCC (Laboratoire de Chimie de Coordination)

205 Route de Narbonne BP 44099, 31077 Toulouse Cedex 4 (France)

Dr. J. Cure, Dr. K. Piettre, Dr. Y. Coppel, V. Collière, Dr. P. Fau Université de Toulouse

UPS, INPT, 31077 Toulouse Cedex 4 (France)

E-mail: yannick.coppel@lcc-toulouse.fr pierre.fau@lcc-toulouse.fr

Dr. J. Cure, Dr. K. Piettre

STMicroelectronics SAS, 10 impasse Thales de Millet 37070 Tours (France)

Dr. E. Beche

PROMES-CNRS

7 rue du four solaire, 66120 Font-Romeu-Odeillo (France)

Dr. J. Esvan

CIRIMAT-ENSIACET

4 allée Emile Monso BP44362, 31030 Toulouse Cedex 4 (France)

Dr. B. Chaudret

LPCNO, INSA-UPS-CNRS

135 avenue de Rangueil, 31077 Toulouse Cedex 4 (France)

Supporting information for this article is available on the WWW under http://dx.doi.org/10.1002/anie.201509715. promising techniques to deposit thin layers in nanoscale patterns, ${ }^{[2]}$ because it allows formation of various compositions of thin and conformal films. ${ }^{[3]}$ In ALD, the growth of metal oxides is obtained by the alternate introduction of water vapor (which forms surface hydroxy groups on the substrate), and metal precursors (in gas phase) which react on it. One of the key parameters of ALD relies on the choice of the metal precursors, which have to present high volatility, thermal and chemical stability, and efficient self-limited reactivity with surfaces. ${ }^{[4,5]}$

Recently, Gordon and co-workers have developed a family of metal-organic amidinate precursors, which are efficient for CVD or ALD deposition. ${ }^{[6]}$ They have reported the conformal deposition of a thin Mn oxide layer on silica support by using bis(N,N'-diisopropylpentylamidinato) manganese(II). ${ }^{[7]}$ They showed that CVD of the Mn metal layer allowed formation of a thin amorphous layer of $\mathrm{MnSi}_{x} \mathrm{O}_{y}$ on silica. Moreover, this layer presented good barrier properties against interdiffusion between $\mathrm{Cu}$ and $\mathrm{SiO}_{2}$, which is a crucial property for copper-based microtechnologies. $^{[8]}$

However, carbon (arising from the precursor ligands) trapped inside the deposited layers may be responsible for the loss of properties of the diffusion barrier layer. For instance, Koike and co-workers reported that the CVD of Mn oxide films induces the presence of an excess of inserted carbon atoms inside the layer, resulting in the progressive loss of adhesion between $\mathrm{Cu}$ and $\mathrm{Mn}$ oxide. ${ }^{[9]}$ To overcome this problem and decrease the cost of film deposition techniques, the requirement for new deposition processes has never been so crucial. Solution chemistry approaches are good candidates to meet these requirements.

Herein, we report the deposition of a carbon-free Mn oxide layer by a metal-organic solution approach: Solution Layer Deposition (SLD). This method involves the reaction in organic solvent between a hydroxylated silica surface and a metal-organic precursor: bis(N,N'-diisopropylpentylamidinato) manganese(II), hereafter named $\mathrm{MnAmd}_{2}{ }^{[6]}$ The surface of silica is functionalized first by an $\mathrm{O}_{2}$ plasma treatment, and exposed to ambient air to form surface hydroxy species. The substrate is then immersed at room temperature into a toluene solution of $\mathrm{MnAmd}_{2}$, which spontaneously reacts with the hydroxy groups of the substrate. This process can be repeated several times, leading to the growth of the Mn oxide layer (Scheme 1). A final annealing ensures the full conversion of $\mathrm{Mn}$ oxide into manganese silicate $\mathrm{MnSi}_{x} \mathrm{O}_{y}$. This method is simple and inexpensive, because the oxide layer is grown in very mild conditions. 


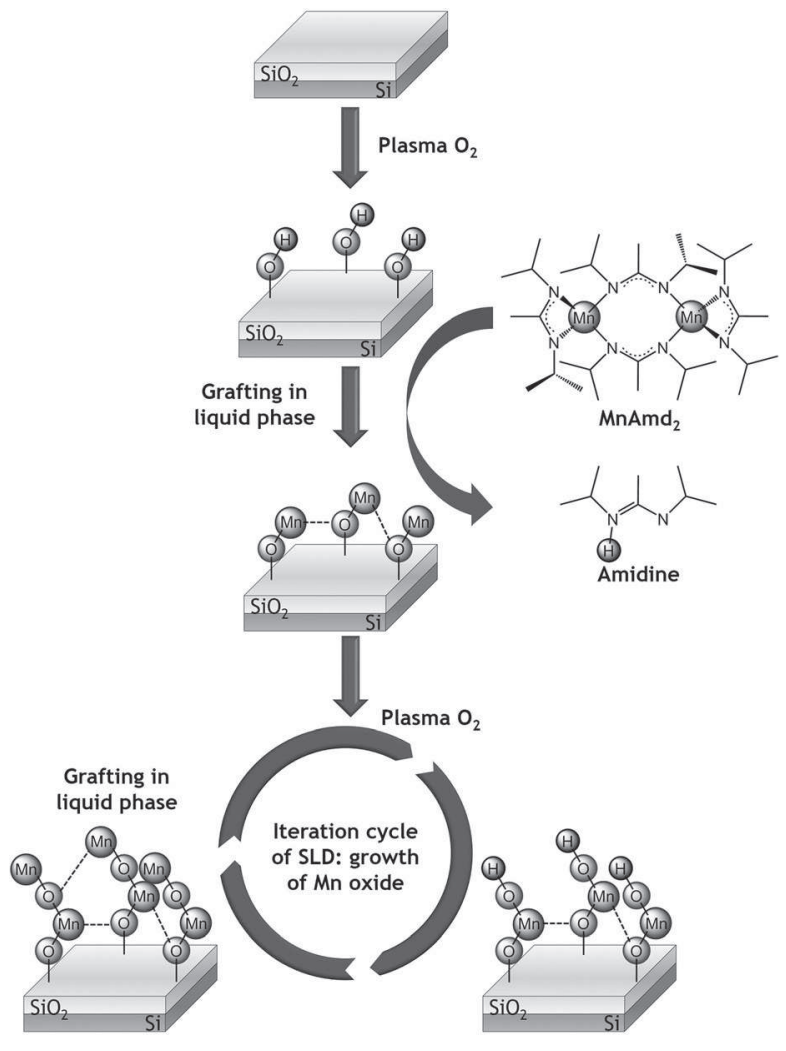

Scheme 1. Principles of manganese oxide growth by SLD.

To examine, by solid state NMR, the nature of the interactions between the silica and Mn oxide layers, one single cycle of the grafting process was performed on silica nanopowders (NPs), which present a similarly high hydroxy group density compared to plasma-treated $\mathrm{SiO}_{2}$ planar substrate. ${ }^{[10]}$ A first ${ }^{29} \mathrm{Si}$ MAS NMR analysis, derived from the Bakhmutov procedure, was achieved with pure silica NPs as reference sample $\mathbf{1}^{[11]}$ Then, the same analysis was performed on silica NPs after contact in $\mathrm{MnAmd}_{2}$ solution (sample 2). Sample 3 consisted of the mechanical mixture of silica NPs and Mn oxide powder ( $10 \%$ by weight) prepared by a simple air oxidation of $\mathrm{MnAmd}_{2}$. The paramagnetic nature of the $\mathrm{Mn}$ oxide powder was confirmed by magnetic measurements (Supporting Information, Figure S5). ${ }^{29} \mathrm{Si}$ magic angle spinning (MAS) NMR spectrum of $\mathbf{1}$ is presented in Figure $1 \mathrm{a}$. Overlapping lines centered at $-92,-100$, and -109 ppm were attributed to different $\mathrm{Si}$ atoms, respectively $\mathrm{Si}\left(\mathrm{Q}_{2}\right), \operatorname{Si}\left(\mathrm{Q}_{3}\right)$, and $\operatorname{Si}\left(\mathrm{Q}_{4}\right)$ in the silica matrix, where units $\operatorname{Si}\left(\mathrm{Q}_{4}\right)$ dominate. The ${ }^{29} \mathrm{Si}$ MAS spectrum of 2 mostly presents an isotropic signal at $-109 \mathrm{ppm}\left(\mathrm{Si}\left(\mathrm{Q}_{4}\right)\right.$ moieties $)$ displaying sideband patterns (Figure $1 \mathrm{~b}$ ). The signals corresponding to $\mathrm{Si}\left(\mathrm{Q}_{2}\right)$ and $\mathrm{Si}\left(\mathrm{Q}_{3}\right)$ moieties show notable intensity decrease: the ( $\mathrm{Si}-$ $\left.\left(\mathrm{Q}_{4}\right)\right) /\left(\mathrm{Si}\left(\mathrm{Q}_{3}\right)+\mathrm{Si}\left(\mathrm{Q}_{2}\right)\right)$ ratio is 89:11 for 2 compared to 78:22 for 1 (Supporting Information, Figure S6). These signals decrease are most probably due to strong Fermi-contact interactions for nuclei located at the surface of silica, and with paramagnetic Mn centers in close proximity, which renders part of them spectrally invisible. ${ }^{[12]}$ Indeed, the ${ }^{29} \mathrm{Si}$ nuclei in the first coordination spheres of the Mn paramagnetic centers, which should present paramagnetic isotropic shifts, are not

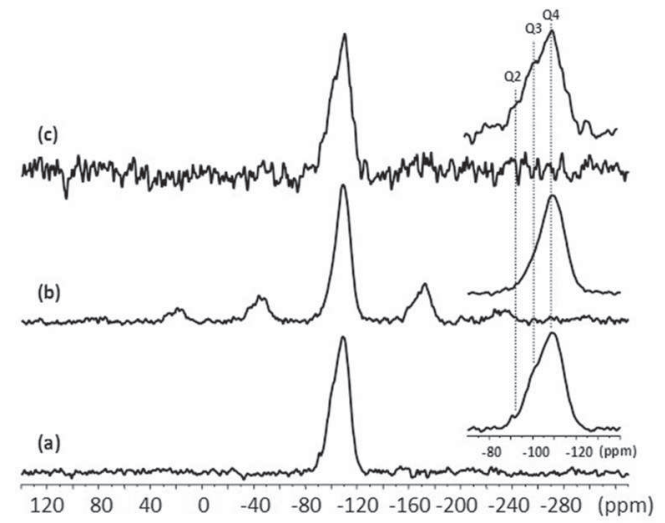

Figure 1. ${ }^{29} \mathrm{Si}$ MAS NMR spectra (spinning rate of $5 \mathrm{kHz}$ ) of: a) pure silica NPs 1; b) silica NPs exposed to one cycle with $\mathrm{Mn} \mathrm{Amd}_{2} 2$; c) mixture of silica NPs and Mn oxide powder 3 .

observed. The intense spinning sideband patterns could be attributed to electron-nucleus dipolar interactions, but also to bulk magnetic susceptibility (BMS) effects. ${ }^{[12]}$ It is noteworthy that dipolar electron-nucleus interactions are a throughspace effect that decreases as a function of $1 / \mathrm{r}^{3}$, and therefore have a significant influence only over short distances. The BMS field is a demagnetization field, arising from larger macroscopic phenomena, that leads to resonance broadenings in solid-state NMR spectra. ${ }^{[12]}$ Since the dipolar coupling and BMS terms depend on the molecular orientations relative to the external magnetic field, they can both lead to spinning sidebands in the MAS NMR spectra. ${ }^{[12]}$ Therefore, these NMR experiments reveal the presence of paramagnetic Mn centers, but are not yet conclusive for chemical interactions between manganese and the silica lattice. ${ }^{[13]}$ To discriminate between both phenomena, a ${ }^{29} \mathrm{Si}$ MAS NMR spectrum of a physical mixture of silica NPs and Mn oxide powder was recorded (sample 3; Figure 1 c). In this case, the Fermi contact and dipolar interactions between ${ }^{29} \mathrm{Si}$ nuclei and the paramagnetic center are excluded, as the electron-nucleus distances become too important, and only BMS effects should impact the NMR spectra. The ${ }^{29} \mathrm{Si}$ MAS spectra of $\mathbf{3}$ did not show the spinning side patterns observed for $\mathbf{2}$, strongly suggesting that the spinning sidebands are associated to the electron-nucleus dipolar interactions. This confirmed the close spatial proximity between ${ }^{29} \mathrm{Si}$ nuclei and paramagnetic $\mathrm{Mn}$ centers in $\mathrm{MnSi}_{x} \mathrm{O}_{y}$. This was obtained after a single grafting cycle of $\mathrm{MnAmd}_{2}$ on $\mathrm{SiO}_{2} \mathrm{NPs}$ in solution at room temperature. This result is also strongly supported by $\mathrm{T}_{1}$ relaxation time measurements, because the $T_{1}$ value decreased from $81 \pm 10 \mathrm{~s}$ for $\mathbf{1}$ to $2.0 \pm 0.3 \mathrm{~s}$ for $\mathbf{2}$ (Supporting Information, Table S1).

Recent studies indicate that $\mathrm{MnSiO}_{3}$ is the most thermodynamically stable compound formed through the interaction of $\mathrm{MnO}_{x}$ and $\mathrm{SiO}_{2} \cdot{ }^{[14,15]} \mathrm{MnSi}_{x} \mathrm{O}_{y}$ forms an interfacial and covalently bound layer on silica, on which a $\mathrm{MnO}_{x}$ layer grows during further cycles of the process (Supporting Information, Figure S7). As for ALD, the SLD process is self-limited: when $\mathrm{MnAmd}_{2}$ molecules have reacted with all the surface hydroxy moieties, the grafting stops. A new $\mathrm{O}_{2}$ plasma treatment 
reactivates the surface, allowing further growth of a Mn oxide layer on the substrate (Figure 2). A STEM-EDS analysis of the cross section of samples prepared with 8 SLD cycles revealed an interfacial zone where both $\mathrm{Mn}$ and $\mathrm{Si}$ atoms were present between $\mathrm{MnO}_{x}$ and $\mathrm{SiO}_{2}$ layers (Figure 2c, d). The Mn oxide layer deposited on silica can be fully converted into $\mathrm{MnSi}_{x} \mathrm{O}_{y}$ by annealing. This reaction was followed by $\mathrm{X}$ Ray Photoelectron Spectroscopy (XPS). ${ }^{[16,17]}$ Annealing at different temperatures and durations were carried out on $40 \mathrm{~nm}$ thick $\mathrm{MnO}_{x}$ layers (Figure 3). The assignment of the $\mathrm{O}$ $1 \mathrm{~s}, \mathrm{Mn} 2 \mathrm{p}$, and $\mathrm{Si} 2 \mathrm{p}$ peaks from the XPS spectra are summarized in Table S3 (Supporting Information). Sample 4

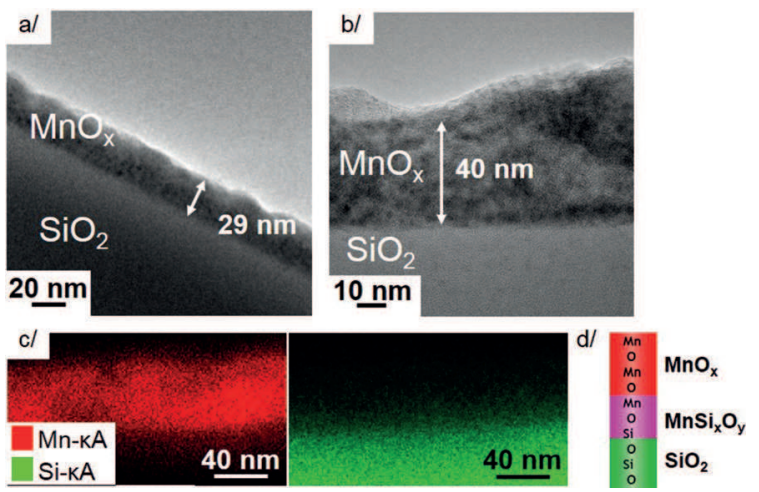

Figure 2. HRTEM observations of cross-sectional sample obtained by a) 4 dips; b) 8 dips; c) STEM-EDS mapping of the 8-dips sample; d) Illustration of the sample.

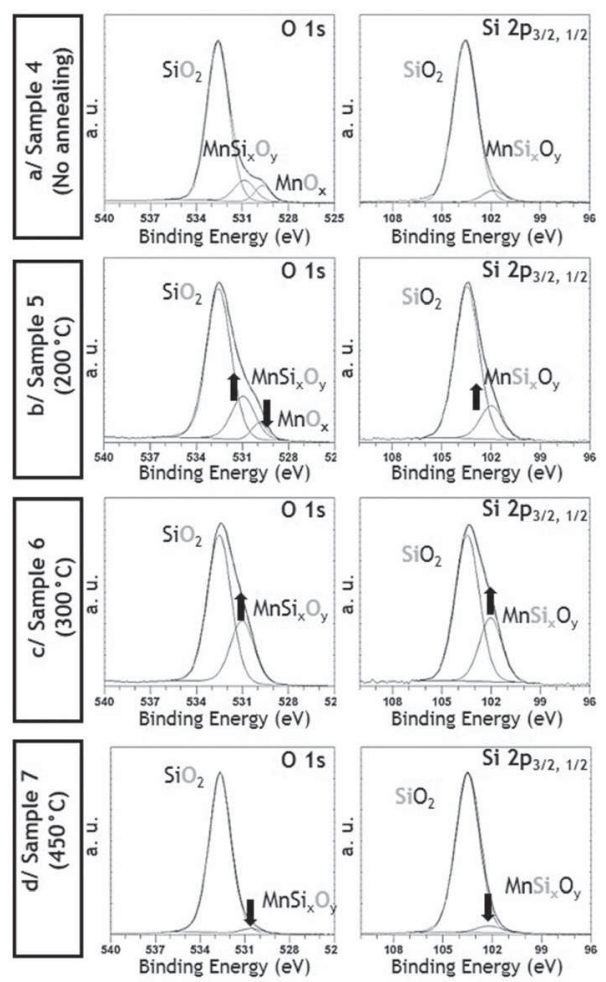

Figure 3. $\mathrm{O} 1 \mathrm{~s}$ and Si $2 \mathrm{p}$ XPS spectra of samples obtained after 8 SLD cycles: a) without annealing; b) annealed at $200^{\circ} \mathrm{C}$; c) $300^{\circ} \mathrm{C}$; d) $450^{\circ} \mathrm{C}$. corresponds to an unannealed $\mathrm{MnO}_{\mathrm{x}}$ layer on silica. The $\mathrm{O} 1 \mathrm{~s}$ and $\mathrm{Si} 2 \mathrm{p}$ signals, respectively located at 531.1 and $102.2 \mathrm{eV}$, are characteristic of a $\mathrm{MnSi}_{x} \mathrm{O}_{y}$ compound (Figure $3 \mathrm{a}$ ). This oxide lies at the $\mathrm{MnO}_{x} / \mathrm{SiO}_{2}$ interface, in agreement with the MAS NMR conclusions. A component corresponding to $\mathrm{MnO}_{x}$ compound was observed at $529.7 \mathrm{eV}$ for $\mathrm{O} 1 \mathrm{~s}$. When the annealing temperature was increased from 200 to $300^{\circ} \mathrm{C}$ (samples $\mathbf{5}$ and 6), the envelope related to the $\mathrm{MnO}_{x}$ compound decreased (Figure $3 \mathrm{~b}, \mathrm{c}$ ). Conversely, $\mathrm{O} 1 \mathrm{~s}$ and $\mathrm{Si}$ $2 \mathrm{p}$ components related to $\mathrm{MnSi}_{x} \mathrm{O}_{y}(531.1$ and $102.2 \mathrm{eV})$ increased. In sample $6\left(300^{\circ} \mathrm{C}\right.$ annealing), the initial $40 \mathrm{~nm}$ thick $\mathrm{MnO}_{x}$ layer is fully converted into $\mathrm{MnSi}_{x} \mathrm{O}_{y}$ layer. This Mn diffusion into $\mathrm{SiO}_{2}$ is confirmed by the STEM-EDS analysis of cross-sectioned sample $\mathbf{6}$ (Supporting Information, Figure S8) where the elementary distributions of $\mathrm{Mn}$ and Si atoms clearly overlap in the same region.

In sample 7 ( $450^{\circ} \mathrm{C}$ annealing), $\mathrm{O}$ 1s and $\mathrm{Si} 2 \mathrm{p}$ XP spectra show a decrease of the components related to $\mathrm{MnSi}_{x} \mathrm{O}_{y}$. This suggests a deeper diffusion of Mn atoms inside the silica layer. Indeed, STEM-EDS observations reveal a progressive diffusion of $\mathrm{MnSi}_{x} \mathrm{O}_{y}$ inside the silica lattice, leading to a higher apparent thickness $(25 \mathrm{~nm})$ of the mixed oxide layer (Supporting Information, Figure S8). Consequently, a silicon oxide-rich layer appears over the top of the mixed oxide layer. Too high annealing temperatures lead to a deeper diffusion of the functional oxide layer. For many applications, the adhesion strength between layers is a key parameter, but the presence of carbon atoms inside the deposited layer can induce a loss of adhesion properties. ${ }^{[9]}$ To quantify the carbon composition into a manganese oxide layer deposited by SLD, Secondary Ion Mass Spectrometry (SIMS) analyses were carried out on samples before and after annealing. The diffusion of $\mathrm{Mn}$ in silica was confirmed in the annealed sample, as the depletion of $\mathrm{O}$ and $\mathrm{Si}$ signals was simultaneously observed with the maximum of Mn content (Figure $4 \mathrm{~b}$ ). The presence of $\mathrm{C}$ atoms only appears at the outermost surface of the sample and not inside the deposited layer (Figure 4; Supporting Information, Figure S9).

The relative intensity of $\mathrm{C}$ to $\mathrm{Mn}$ is about 1:100 in both cases, and appears to be independent of the annealing. This surface carbon may be due to the adsorption of carbon species from the ambient air environment. This low carbon content in the growing film is related to the very mild grafting process in SLD, where the Mn precursor is gently de-coordinated on hydroxy groups on the substrate, and byproducts are removed in the solvent medium.

In conclusion, we have presented an inexpensive and efficient solution deposition technique (SLD) that allows preparation of a Mn oxide layer on a silica substrate. During the first SLD deposition cycle, $\mathrm{O}_{2}$ plasma treatment of the substrate, followed by air exposure, generates hydroxy moieties that react with the $\mathrm{MnAmd}_{2}$ precursor in solution. Owing to the high reactivity of $\mathrm{MnAmd}_{2}$ to silicon hydroxy groups, the $\mathrm{Mn}$ atoms are covalently bound to silica and spontaneously form $\mathrm{MnSi}_{x} \mathrm{O}_{y}$, as confirmed by MAS NMR and XPS studies. The repetitive steps of plasma treatment followed by dipping the substrate in solution precursor lead to the growth of a Mn oxide layer. It is noteworthy that SIMS analyses indicated the lack of carbon incorporation in the Mn 

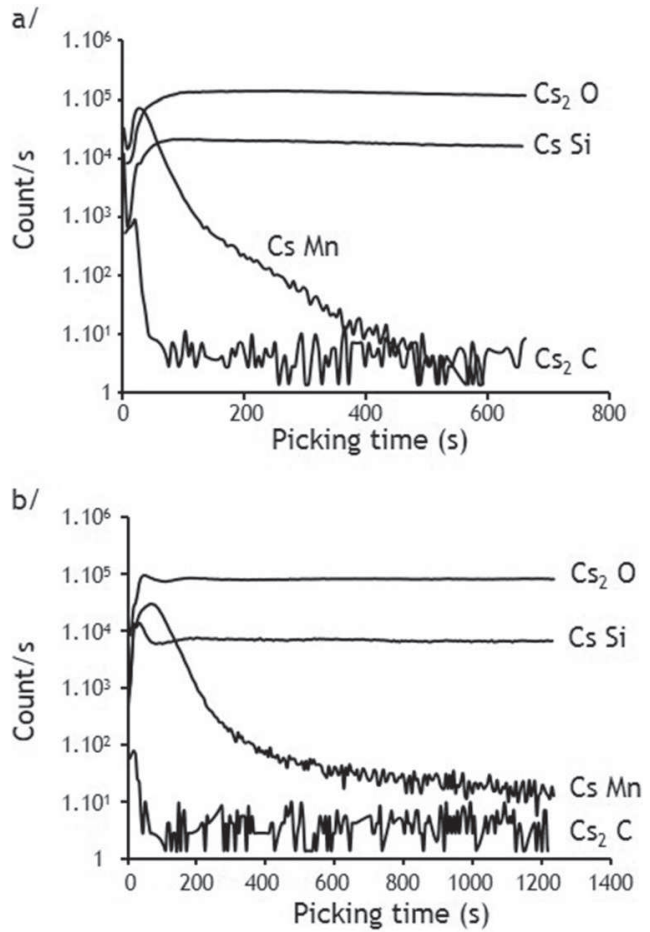

Figure 4. SIMS analyses of $40 \mathrm{~nm} \mathrm{MnO}_{x}$ samples a) before and b) after annealing: $450^{\circ} \mathrm{C}, 4.5 \mathrm{~h}$.

oxide layer obtained by this mild solution deposition technique. A controlled annealing $\left(300^{\circ} \mathrm{C}\right)$ of the Mn oxide layer induces the diffusion of $\mathrm{Mn}$ atoms into the silica lattice, leading to a full conversion into $\mathrm{MnSi}_{x} \mathrm{O}_{y}$. Such layers can be used in microelectronics applications as a diffusion barrier layer between copper and silica. ${ }^{[8]}$ A copper layer, prepared by decomposition of a copper amidinate precursor according to a previously described method ${ }^{[18]}$ has been deposited on a silica substrate functionalized with one cycle of the SLD method. After a subsequent annealing at $300^{\circ} \mathrm{C}$, no evidence for copper diffusion was observed, thus demonstrating the very efficient barrier property of our $\mathrm{MnSiOx}$ layer (Supporting Information, Figure S10). The SLD method allows for a much larger choice of precursors compared with ALD. The amidinate family are good candidates for SLD deposition. We also showed, in other experiments, that zinc amidinate allows deposition of $\mathrm{ZnO}$ layers by using the same process. Additionally, many other metal complexes that are reactive towards hydroxy groups can be applied using this method, such as metal alkyls which are highly reactive and would be easily implemented in a liquid phase and low temperature process. Indeed, thermal stability and high volatility are not required properties for precursors employed at room temperature and atmospheric pressure in solution processes. The SLD is therefore a facile and very promising method for the deposition of functional metal oxide layers on various surfaces.

\section{Acknowledgements}

The authors acknowledge STMicroelectronics (Tours) SAS (Dr. Benoit Riou and Dr. Céline Bondoux), and ANRT for funding, CNRS and Université Fédérale de Toulouse, UT3 Paul Sabatier for their support. We also thank Dr. Theresa Hungria for SIMS analyses.

Keywords: contamination-free - magic angle spinning NMR . manganese amidinate $\cdot$ metal oxide layers $\cdot$ solution deposition

How to cite: Angew. Chem. Int. Ed. 2016, 55, 3027-3030 Angew. Chem. 2016, 128, 3079-3082

[1] T. Usui, H. Nasu, S. Takahashi, N. Shimizu, T. Nishikawa, M. Yoshimaru, H. Shibata, M. Wada, J. Koike, IEEE Trans. Device Mater. Reliab. 2006, 53, 2492-2499.

[2] E. Rauwel, G. Clavel, M.-G. Willinger, P. Rauwel, N. Pinna, Angew. Chem. Int. Ed. 2008, 47, 3592-3595; Angew. Chem. 2008, 120, 3648-3651.

[3] M. Leskelä, M. Ritala, Angew. Chem. Int. Ed. 2003, 42, 55485554; Angew. Chem. 2003, 115, 5706-5713.

[4] K. B. Ramos, M. J. Saly, Y. J. Chabal, Coord. Chem. Rev. 2013 , 257, $3271-3281$.

[5] S. W. Lee, B. J. Choi, T. Eom, J. H. Han, S. K. Kim, S. J. Song, W. Lee, C. S. Hwang, Coord. Chem. Rev. 2013, 257, 3154-3176.

[6] B. S. Lim, A. Rahtu, J.-S. Park, R. G. Gordon, Inorg. Chem. 2003, 42, $7951-7958$.

[7] R. G. Gordon, H. Kim, Y. Au, H. Wang, H. B. Bhandari, Y. Liu, D. K. Lee, Y. Lin, Adv. Met. Conf. 2008 Proc. 2009, 321-329.

[8] A. A. Istratov, C. Flink, E. R. Weber, Phys. Status Solidi B 2000, 222, $261-277$.

[9] V. Dixit, K. Neishi, N. Akao, J. Koike, IEEE Trans. Device Mater. Reliab. 2011, 11, 295-302.

[10] H. Provendier, C. C. Santini, J.-M. Basset, L. Carmona, Eur. J. Inorg. Chem. 2003, 2003, 2139-2144.

[11] V. Bakhmutov, B. Shpeizer, A. Clearfield, Magn. Reson. Chem. 2006, 44, $861-867$.

[12] V. Bakhmutov, Chem. Rev. 2011, 111, 530-562.

[13] A. Kubo, T. Spaniol, T. Terao, J. Magn. Reson. 1998, 133, 330 340.

[14] P. Casey, J. Bogan, J. Lozano, P. Nellist, G. Hughes, J. Appl. Phys. 2011, 110, 124512.

[15] P. Casey, J. Bogan, B. Brennan, G. Hughes, Appl. Phys. Lett. 2011, 98, 113508 .

[16] J. Koike, M. Wada, Appl. Phys. Lett. 2005, 87, 041911.

[17] K. Matsumoto, K. Neishi, H. Itoh, H. Sato, S. Hosaka, J. Koike, Appl. Phys. Express 2009, 2, 036503.

[18] K. Piettre, V. Latour, O. Margeat, C. Barrière, V. Collière, C. Anceau, J. B. Quoirin, B. Chaudret, P. Fau, Mater. Res. Soc. Symp. Proc. 2010, 1249, F1203-1202.

Received: October 16, 2015

Revised: December 18, 2015

Published online: January 28, 2016 